University of Washington Tacoma

UW Tacoma Digital Commons

\title{
Bridging the Gap: Addressing the Mental Health Needs of Underrepresented Collegiate Students at Psychology Training Clinics
}

\author{
Alyssa M. Ramírez Stege \\ University of Washington Tacoma, ramstege@uw.edu \\ Nickolas D. Frost \\ Stephanie R. Graham \\ Tiffany Jones \\ Tyson Pankey
}

See next page for additional authors

Follow this and additional works at: https://digitalcommons.tacoma.uw.edu/ias_pub

\section{Recommended Citation}

Frost, N. D., Graham, S. R., Ramírez Stege, A. M., Jones, T., Pankey, T., \& Martinez, E. M. (2020). Bridging the Gap: Addressing the Mental Health Needs of Underrepresented Collegiate Students at Psychology Training Clinics. Training and Education in Professional Psychology, 14(2), 138-144. https://doi.org/ 10.1037/tep0000282

This Article is brought to you for free and open access by the School of Interdisciplinary Arts and Sciences at UW Tacoma Digital Commons. It has been accepted for inclusion in SIAS Faculty Publications by an authorized administrator of UW Tacoma Digital Commons. 
Authors

Alyssa M. Ramírez Stege, Nickolas D. Frost, Stephanie R. Graham, Tiffany Jones, Tyson Pankey, and Elizabeth M. Martinez

This article is available at UW Tacoma Digital Commons: https://digitalcommons.tacoma.uw.edu/ias_pub/1170 
Bridging the Gap: Addressing the Mental Health Needs of Underrepresented Collegiate Students at Psychology Training Clinics 


\begin{abstract}
Mental health treatment utilization on college campuses remains disproportionately low among underrepresented students (UR; i.e., racial/ethnic minorities, first generation college students, and students from low-income families). Additionally, UR students report that factors including stigma, long wait-times, and costs are barriers to accessing treatment. Given these trends, new methods to bolster the utilization of counseling services among UR college students are needed. Concurrently, there is a call for psychology training programs to increase their efforts in preparing health service psychologists to work with culturally diverse populations including UR students. Psychology training clinics may be an additional resource on campuses that can be useful in meeting both of these needs. We present a program evaluation of 4-year partnership between a counseling psychology department training clinic and an academic division serving UR students at a large Midwestern university. Two quantitative metrics, including service utilization hours by UR students $(2,020)$ and direct service hours accrued by clinical trainees $(1,266)$, highlight the benefits of the partnership. A social justice framework and implications for training programs interested in developing similar partnerships are discussed.
\end{abstract}

Key Words: Psychology Training Clinics, college mental health, underrepresented students, social justice training

Public Significance Statement: This program evaluation describes a formalized partnership between a psychology training clinic and an academic division supporting underrepresented (UR) college students. The partnership, developed within a social justice framework, increased the mental health treatment utilization rates of UR students while also increasing supervised clinical training opportunities for psychology doctoral students in working with diverse clients. 
Underrepresented students (UR), including - but not limited to - racial/ethnic minorities, first generation college students, and students from low-income families, are statistically underrepresented in higher education. The federal administration has encouraged post-secondary institutions to not only "attract and admit" UR students, but to "support and retain" these students once on campus (U.S. Department of Education, 2016, p. 1). Post-secondary institutions have developed many efforts, including scholarship programs, to specifically recruit UR students and promote a diverse student body on their campuses (U.S. Department of Education, 2016). While these efforts have increased UR students' educational opportunities, UR students often face non-financial barriers to education (Byrd \& McKinney, 2012). A major dilemma facing university administrations and scholarship programs nationwide is how to address mental health concerns for UR students.

At the same time, there is a call for training programs in professional psychology to increase training opportunities that address societal inequities and provide culturally competent mental health care to underserved populations (Scheel, Stabb, Cohn, Duan, \& Sauer, 2018). Historically, counseling psychology training programs have defined themselves by their attention to multiculturalism and social justice frameworks that acknowledge the influence of power, privilege, and oppression on the individual and collective wellbeing (Scheel et al., 2018). Given this niche, a key opportunity exists for counseling training programs to create new and innovative approaches to clinical training that meet the wide-ranging needs of diverse populations, including UR students. However, examples of such training initiatives with clear outcome metrics are rare. We present a program evaluation of an innovative campus partnership that utilized a counseling psychology training program's training clinic with two related goals: 1) 
facilitate mental health service utilization for UR students and 2) increase clinical training opportunities for psychology graduate trainees.

\section{Mental Health Needs of UR Students}

It has been well documented that UR college students can experience a unique set of psychosocial and emotional challenges within institutions of higher learning. For example, students of color - particularly at predominantly White institutions - have increased awareness of issues related to racism or injustice and, therefore, may perceive the campus climate as more unwelcoming and unsupportive compared to their White counterparts (Pieterse, Carter, Evans, \& Walter 2010). Mental health problems can be exacerbated (or precipitated) by such negative perceptions of campus climate or exposure to prejudice, leading to depression, anxiety, and/or social isolation (Ancis, Sadlacek \& Mohr, 2000; Bernard, Lige, Willis, Sosoo, \& Neblett, 2017). For UR students, the normative stressors of college may be compounded by their unique social experiences within the broader campus community including the occurrence of negative race (Smith, Allen \& Danley, 2007) and class-related (Locke \& Trolian, 2018) experiences on campus.

Paradoxically, research in mental health service utilization has highlighted significant disparities in seeking psychological help. UR undergraduate students use mental health services infrequently compared to non-minority students, even when reporting more distress (Cheng, Kwan, \& Sevig, 2013). Ethnic minorities and first-generation college students may also hold less favorable attitudes toward seeking psychological help (Garriott, Raque-Bogdan, Yalango, Schaefer Ziemer, \& Utley, 2017).

\section{Challenges to Addressing UR Student Needs}


Systemic methods to address the mental health needs of UR students have historically been underdeveloped compared to other support services. For example, locally and federallyfunded scholarship programs typically offer academic support upon entry into higher education and throughout a student's time at an institution (U.S. Department of Education, 2008). However, few programs (if any) offer concomitant mental health support services. The provision of mental health support is typically delegated to college counseling centers, where growing demands are beginning to outpace resources (Center for Collegiate Mental Health [CCMH], 2018; Xiao et al., 2017).

Recent data has noted a 30\% increase in demand for mental health services on college campuses (CCMH, 2018; Xiao et al., 2017). These increases are a challenge for counseling centers as they struggle to meet the needs of a growing body of consumers (CCMH, 2018). Other systemic challenges include the availability of culturally diverse clinicians and client waitlists (National Alliance on Mental Illness [NAMI], 2012). A number of studies suggest that UR students, particularly racial/ethnic minorities, would prefer to have the option to work with a clinician of a similar cultural background (Cabral \& Smith, 2011). A lack of staff diversity could be a plausible contributor to disparities in utilization (Association of University and College Counseling Centers Directors [AUCCD], 2017; Hayes et al., 2011). In addition, 34\% of college counseling centers report having waitlists (AUCCCD, 2017). Some UR students, however, are less likely to return to treatment after experiencing long wait times, and are more likely to be dissatisfied with the services they do subsequently receive (Levy, Thompson-Leonadelli, Smith, Grant, \& Coleman, 2005). Professional psychology training programs that house their own training clinics are well equipped to address these challenges.

\section{An Additional Resource: Psychology Training Clinics}


There are over 390 accredited graduate training programs in professional psychology (e.g., clinical, counseling, school, and combined programs) across universities and colleges in the U.S. (American Psychological Association Commission on Accreditation, 2018). Many of these programs have training clinics administratively housed within academic departments rather than in university and college health centers. The Association of Psychology Training Clinics (APTC) reported approximately 203 training clinics within their membership in 2019 (Keenan-Miller, 2019). Psychology training clinics often have an important role in the clinical training of master's and doctoral-level students in psychology while also providing mental health services to their communities including the student body of the home institution. Psychology graduate programs have an opportunity to realize a practical application of social justice principles by creating more formalized partnerships with university academic divisions serving UR students.

\section{Exemplar Partnership}

The partnership began in the summer of 2014 when a campus division at a large predominately White institution in the Midwestern U.S. initiated conversations with the Department of Counseling Psychology about garnering additional mental health support for its students. Specifically, the division, whose mission is to promote a diverse and inclusive learning community including the management of several scholarship programs for UR students (e.g., merit-based scholarships and need-based scholarships for first-generation college students, racial and/or ethnic minority students), needed more intensive mental health services. This request was in response to a division student death, several racial bias incidences on campus, and the underutilization of campus mental health resources. The division leadership and department faculty formalized the relationship between the division and the department's training clinic so that division students could receive mental health services at the training clinic free of charge. 
The division provided financial support to the department by funding one advanced graduate student (increased to two paid positions in year 3) to serve as the primary clinician at the training clinic for division students (referred to as community support specialists [CSS]; see below).

Department faculty and graduate students developed key social justice aspects of the partnership.

Social justice framework. A review of key social justice models for counseling psychology training was conducted in the initial phase of the partnership. The literature suggests that the following major factors comprise multicultural and social justice work: (a) selfevaluation, (b) critical consciousness, (c) building partnerships, (d) giving voice, (e) power sharing and developing trust with clients and community partners, (f) building on strengths, and (g) student and client empowerment (Constantine, Hage, Kindaichi, \& Bryant, 2007; Goodman et al., 2004). Constantine and colleagues (2007) also emphasized the role of questioning and challenging assumptions of psychotherapeutic intervention practices, and increasing knowledge of culturally relevant indigenous models of health and healing. We focused on five key principles within a social justice approach: 1) development of partnerships and relationships outside the therapeutic encounter, 2) participation in advocacy and community outreach, 3) engagement in continuous self-evaluation and consciousness raising, 4) empowerment of student trainees, clients, and program directors, and 5) giving voice to trainees and clients. Thus, we see the partnership as a communitarian justice model that incorporates advocacy, outreach, and prevention programming in addition to individual and group psychotherapy services (Vera \& Speight, 2003).

Treatment model. Efforts were made to inform all division students about the mental health services available to them at the training clinic upon their entry to campus. This information was provided at several other time points throughout their undergraduate careers 
(e.g., scholarship program meetings, outreach events). Division students seeking counseling services contacted the clinic via phone and were screened during a brief triage phone call and then the case was assigned based on client preferences (e.g., gender of clinician, asking for a CSS by name, etc.) and schedule matching. This mimicked the typical triage system where potential clients are asked briefly about referral source, presenting concerns, and risk to self or others with the exception of matching requests from division students for working directly with a specific CSS. A formal referral was not needed by division students yet many reported anecdotally that they were referred by member of division staff, met one of the CSS at an outreach event, or were encouraged to seek counseling by another division student client.

We tailored clinical policies and procedures to increase accessibility for division students. There were no session fees given the financial model. This deviated from the sliding scale fee structure used at the clinic for non-division clients (clients typically pay $\$ 5-10$ per treatment session and the ability to wave fees for clients in financial need). Moreover, there was administrative integration of the scholarship programs with the training clinic (e.g., regular bidirectional communication between division and specific scholarship program administration and clinic staff regarding general issues, needs, utilization, etc.), and embedding CSS within the student community (see below). The smaller scale of the training clinic gave more latitude to accommodate documented UR student needs (e.g., reduced wait times, weekly sessions, honoring student requests for working with specific therapists).

Community support specialists. The community support specialists (CSS) were advanced counseling psychology doctoral students (usually in program year 3-5) who themselves identified as ethnic minorities, and expressed interest in working with diverse groups. Only ethnic minorities were considered for the CSS because we sought to create a funded training 
opportunity for minority trainees within the counseling department. Equally important, the ethnic identity of CSS was hypothesized by our division partner to play a critical role in CSS integration into student the community and creating credibility of services. CSS applied through a formal application and interview process, similar to a practica application process. The CSS were appointed as 12-month program assistants funded by the division overseeing the scholarship programs and were supervised by the department clinic director and clinic staff (e.g., other faculty supervisors). CSS met the individual mental health needs of students within the division a) as therapists at the training clinic, b) visible members of the student community (i.e., graduate students of color, liaisons to the academic division), and c) a resource to division staff and other frontline student support staff. The CSS consulted with division program staff to advocate and provide psychoeducation related to students' mental health needs, conducted outreach events to decrease anonymity of CSS, and developed presentations for division students on different mental health-related topics.

The CSS embedded therapist model is similar to previously developed counselor-inresidence programs (see Orchowski et al., 2011) in which counselors are available to support both students and staff through prevention and intervention efforts. In our model, the CSS actively engage in student activities and programs for outreach opportunities to address student concerns and provide consultation as requested. A recurring outreach activity for CSS included attending monthly student community meetings where psychoeducation was presented (e.g. sleep hygiene). From the perspective of the student, CSS are a part of the division and its staff.

Training and supervision. Since its creation, the partnership has been under the administrative supervision of the training clinic director, a clinical faculty member in the department and a core program faculty of the doctoral program in Counseling Psychology. 
Department faculty offer regular consultation regarding aspects of the partnership (e.g., selection of CSS, managing increasing demand for services) and other administrative support, as needed.

The partnership created an opportunity to expand our training and supervision to include a greater emphasis on the provision of culturally competent treatment. The format of supervision included a weekly hour of one-on-one supervision and 4.5 hours of weekly group supervision, which is the standard for all trainees at the clinic. CSS supervision was also supplemented by an additional hour focused specifically on systemic and individual health equity issues for UR students (6.5 hours per week total). Supervision was not manualized and weekly content depended on several factors including CSS caseload and client need. Formalized training topics for all clinic staff included trauma-informed care, complex trauma, responding to client disclosures about racist experiences on campus, social class in psychotherapy, and the use of self-disclosure in psychotherapy.

The clinical supervision of the CSS is a critical component of the partnership. Given the nature of working in small communities, particularly communities of color, many of the CSS have shared experiences with their clients. This introduces challenges for the therapist who must manage their own countertransferential reactions to ensure competent service delivery (Shafranske \& Falender, 2008). The primary clinical supervisor of the CSS has been the clinic training director, a white cisgender queer woman with over 11 years of experience in clinical service delivery to undergraduate students from diverse sociocultural backgrounds. Supervision with a psychologist who has expertise in working with UR student populations has been essential to the partnership's success. Moreover, it was important to center sociocultural identities and context in supervision so a critical, post-colonial resilience-based approach was utilized (see Hernandez \& McDowell, 2010). 


\section{Evaluation of Program}

We were interested in two evaluative metrics: a) clinical training benefits, and b) service utilization by UR students. The former was measured in terms of service hours accrued by CSS over the 4 years of the partnership. We also examined treatment utilization by division students. Service utilization data from the training clinic are from August $31^{\text {st }}, 2014$ to July $30^{\text {th }}, 2018$-the first 4 years of the partnership. Division student demographics, number of attended counseling appointments, no-show/cancellation rates are compared with non-division clients receiving usual care at the training clinic.

Since the clinic operated normally as an outpatient sliding-scale fee clinic during this partnership, division and non-division comparison groups were formed naturally. That is, nondivision clients were receiving routine individual mental health care at the clinic with clinicians other than the CSS as they otherwise would. They included adult community members and university students not part of the division. On the other hand, division clients seeking treatment were assigned a CSS counselor with the policy and procedure adaptions. Aggregate service utilization rates between these two groups are compared and also compared with college counseling centers at universities of comparable size (AUCCCD, 2017).

\section{Division Student Demographics}

In total, 127 unique division students sought individual counseling (165 treatment episodes) at the training clinic between 2014 and 2017. These clients were primarily female $(64 \%)$ and ethnic minorities $(87 \%)$. We focus on ethnic minority and gender here due to data availability. As can be seen in Table 1, African-American students comprised the largest ethnic minority group across the 4 years, followed by Latinx, Caucasians, Asian-Americans, and Multiracial students, respectively. From the beginning, the partnership shifted the demographic 
composition of the training clinic's clientele. For example, at the start of the partnership in 2014, the training clinic's client base was $20 \%(N=11)$ ethnic minority. The addition of the division students who sought treatment immediately raised this percentage to $36 \%$ in the same year. The cumulative percentage of ethnic minorities at the training clinic remained between $36 \%$ and $57 \%$ across the four years (Table 1).

\section{[Insert Table 1]}

Client volume at the clinic increased as a result of the partnership. In the latter two years of the partnership, an additional CSS position was created ( 2 total) to serve a larger number of UR students. Overall client volume, measured in absolute number of clients undergoing treatment at the training clinic was also substantially increased. Division students accounted for $41 \%(N=165)$ of all clients (389 total) at the training clinic across the 4 years. While division students represented only $28 \%(\mathrm{~N}=21)$ in the first year of the partnership, by the 2017-2018 academic year, more than half of all clients seen at the training clinic were division students $(\mathrm{N}=$ 72; 53\%). Total clinic volume grew from 75 clients in 2014, to 136 by 2017.

\section{Service Utilization Rates}

Division students attended a total of 2,020 hours of individual psychotherapy sessions which represented $42 \%$ of the clinic's total service hours. The average (mean) number of sessions per division student was $12.24(\mathrm{SD}=7.26)$, and ranged from 2 to 28 sessions. Rates of session attendance for division students as a whole at the training clinic are displayed in Table 2. Division students exhibited high treatment attendance with low no-show $(\mathrm{M}=1.28, \mathrm{SD}=1.52)$ and cancellation $(\mathrm{M}=1.55 ; \mathrm{SD}=1.54)$ rates. A significant portion of division students' treatment episodes were 15 sessions or more $(40 \% ; N=66)$. The number of attended appointments per client was negatively correlated with no-showed appointments for division 
students $(r=-0.10)$. That is, the more counseling sessions a student attended, the less they noshowed for an appointment.

\section{[Insert Table 2]}

There was no significant difference $(d=0.08)$ between division and non-division clients in number of average sessions attended, nor was there a significant difference for cancellation rates $(d=0.0)$. A large difference was exhibited, however, for no-show rates between division and non-division students $(d=-0.60)$.

\section{Community Support Specialists Service Hours}

Service hours accrued by CSS provide a quantitative metric of the clinical training benefit from the partnership. CSS engaged in both face-to-face individual counseling as well as advocacy, outreach and consultation for students in the scholarship programs within the division. These activities all counted toward pre-doctoral internship training hours. A total of 5 advanced doctoral trainees ( 2 male, 3 female) successively held the CSS position across 4 years. In total, CCS trainees accrued 1,266 face-to-face contact hours, 242 consultation hours, 80 outreach hours, and spent 55 engaging in student advocacy. Outreach included presentations on mental health topics to division students, mental health seminars at program retreats, and large scale mental health needs assessments for the division. Consultation included CSS coordinating collaborative care with external mental health professionals and other student support resources on campus (e.g. connecting students with psychiatric services). Advocacy hours included advocating for division students at the University level (e.g. developed mental health crisis protocols for staff to follow).

[Insert Table 3] 
While most (68\%) clinical training programs begin practicum placements for trainees in their second year of training, it is unclear how often students get exposure to diverse populations in their first or subsequent practicum placements (Hatcher, Wise \& Grus, 2015). Given that all division students were first-generation, low-income, or ethnic minorities, all clinical contact hours accrued by CSS were with diverse populations.

\section{Discussion}

The metrics of service utilization among UR students and the clinical service hours accrued by graduate trainees suggest this model was effective. More specifically, the acceptability of our model for UR students was evidenced by their high utilization rates.

Considering that many of these students may have not sought treatment without this partnership, this utilization rate is noteworthy. The significant difference in no-show rates between division and non-division students could be interpreted several ways including that providing services at no-cost leads to poor treatment retention. However, these effects appear to be time variant. That is, the average ratio of no-show to attended appointments was lower in the first two years ( $\mathrm{M}=$ $0.10)$, than the second two years $(\mathrm{M}=0.23)$ when services were made available to larger number of division students. This difference could have implications for scalability of such partnerships, but likely reflects variability in mental health service needs for larger populations. This interpretation is strengthened by the fact that neither division students or non-division clients were charged for no-showed appointments.

Training metrics reveal a highly beneficial partnership for trainees in terms of direct and indirect service hours. Non-therapy activities included acting in the role of change agent on the university campus and participating in student programming in accordance with a social justice framework (Vera \& Speight, 2003). 
Additional Considerations. The CSS positions are graduate student assistantships (i.e., paid clinical appointments); thus, sustainable funding sources are a consideration for training clinics hoping to develop similar partnerships. We believe that university administrations particularly at PWI's - may be inclined to fund these positions due to their relatively low cost and potential effects on UR student academic retention. Mental health support for UR students may be a wise investment for universities seeking more holistic approaches to improving UR student retention and promoting academic excellence.

Implementation and sustainability are important considerations for development of similar partnerships. One implementation challenge was differentiating services of the training clinic from the college counseling center at the university level. This is especially important for obtaining long term university funding from third parties (i.e. sustainability). Developing a complimentary service relationship with the counseling center (e.g. regular bidirectional case referral), and informing third parties about the unique features of training clinic (i.e., not duplicating university services) was critical to solving this challenge. Additionally, with increased demand and need for longer-term counseling services, clinic resources may need to be supplemented including adding another CSS position, increasing hours of service.

Another consideration is the ethnic identity of graduate students who served as CSS. We made this opportunity exclusively available to ethnic minority advanced doctoral trainees. We hypothesized that the ethnic identity of CSS played a critical role in facilitating of service utilization given that most of the division clients were themselves ethnic minorities. Many ethnic minority groups express preference for a same-race therapist (Cabral \& Smith, 2011). Although ethnic match has occasionally failed to predict treatment outcomes, the match may motivate initial treatment seeking for ethnic minority clients. 
The overall training benefits of this partnership were far reaching, and not limited to those trainees who served as CSS. For example, while CSS engaged in 1,266 hours of direct therapy, division students attended a total of 2,020 hours. Thus, 754 hours of therapy were provided to the overflow clients by non-CSS trainees at the clinic. This overflow provided other trainees with exposure to diverse populations in a clinical setting and changed the landscape of the training clinic as a whole. The increases in diversity-related discussions in supervision and in case formulation and treatment planning are incalculable. Rates of service utilization for diverse populations at training clinics writ large is not known at this time; however, division students constituted nearly half of all clinical hours at our training clinic during this partnership. Thus, the partnership both helped fill the social justice mission of the department and the clinic and placed diversity as a centerpiece of clinical training.

Finally, another advantage of this partnership can be felt at the program recruitment level, both for the division scholarship programs and the department training program. The potential to work at the training clinic and to work as a CSS has been cited by prospective doctoral students as a factor in their decision to join our department. In addition, division program administrators share the partnership with our clinic with their prospective students as a recruitment tool and supportive resource available to their students during their transition to the university. Division UR students are, therefore, introduced to the clinic resources early in their experience as an undergraduate student via our proactive partnership.

Limitations. The success of this partnership should also be interpreted in light of some limitations of our evaluation. First, we did not utilize routine treatment outcome monitoring because the technology was not available at the clinic when the partnership began. We have since begun collecting outcome data including academic outcomes and rates of symptom 
improvement to present at a later time. In addition, because only a small number $(n=5)$ of clinical trainees held the CSS position, utilization rates may be due to therapist effects as opposed to other factors (Xiao et al., 2017). However, such therapist effects would be desirable to the extent that they facilitate service utilization. If similar partnerships are developed at other universities, research could examine the role of therapist effects on treatment outcomes. Such future research could contribute greatly to multicultural training. We did not have data regarding division students socioeconomic background or college generational status, which limits the scope of our evaluation. Nonetheless, the success of this partnership provides a clearly measurable, and replicable example how to infuse social justice into clinical training that also meets a growing need on many U.S. university and college campuses. 


\section{References}

American Psychological Association Commission on Accreditation (2018). Commission on accreditation 2018 annual report online summary data: Doctoral programs. Retrieved from https://www.apa.org/ed/accreditation/about/research/2018-doctoral -summary/pdf

Ancis, J. R., Sedlacek, W. E., \& Mohr, J. J. (2000). Student perceptions of campus cultural climate by race. Journal of Counseling \& Development, 78(2), 180-185. doi: 10.1002/j.1556-6676.2000.tb02576.x

Association for University and College Counseling Center Directors (2017). The Association for University and College Counseling Center Directors Annual Survey. Retrieved from https://www.aucced.org/assets/documents/Governance/2017\%20aucccd\%20surveypublic-apr26.pdf

Bernard, D. L., Lige, Q. M., Willis, H. A., Sosoo, E. E., \& Neblett, E. W. (2017). Impostor phenomenon and mental health: The influence of racial discrimination and gender. Journal of Counseling Psychology, 64, 155-166. doi: $10.1037 / \operatorname{cou} 0000197$

Blanco, C., Okuda, M., Wright, C., Hasin, D. S., Grant, B. F., Liu, S. M., \& Olfson, M. (2008). Mental health of college students and their non-college-attending peers: Results from the National Epidemiologic Study on Alcohol and Related Conditions. Archives of General Psychiatry, 65, 1429-1437. doi:10.1001/archpsyc.65.12.1429

Boone, M. S., Edwards, G. R., Haltom, M., Hill, J S., Lian, Y., Mier, S. R.... Yau, T. Y. (2011). Let's talk: Getting out of the counseling center to serve hard-to-reach students. Journal of Multicultural Counseling and Development, 39, 194-205. doi: 10.1002/j.2161 
1912.2011.tb00634.x

Byrd, D. R., \& McKinney, K. J. (2012). Individual, interpersonal, and institutional level factors associated with the mental health of college students. Journal of American College Health, 60, 185-193. doi:10.1080/07448481.2011.584334

Cabral, R. R., \& Smith, T. B. (2011). Racial/Ethnic matching of clients and therapists in mental health services: A meta-analytic review of preferences, perceptions and outcomes. Journal of Counseling Psychology, 58(4), 537-554. doi: 10.1037/a0025266

Center for Collegiate Mental Health. (2018). 2017 Annual Report (Publication No. STA 18-166). Retrieved from https://sites.psu.edu/ccmh/files/2018/02/2017_CCMH_Report1r4m88x.pdf

Cheng, H. L., Kwan, K. L., \& Sevig, T. (2013). Racial and ethnic minority college students stigma associated with seeking psychological help: Examining psychocultural correlates. Journal of Counseling Psychology, 60, 98-111. doi: 10.1037/a0031169

Choi, N. Y., \& Miller, M. J. (2014). AAPI college students' willingness to seek counseling: The role of culture, stigma, and attitudes. Journal of Counseling Psychology, 61, 340 -351. doi: $10.1037 /$ cou0000027.

Cokley, K., Smith, L., Bernard, D., Hurst, A., \& Jackson, S. (2017). Imposter feelings as a Moderator and mediator of the relationship between perceived discrimination and Mental health among racial/ethnic minority college students. Journal of Counseling Psychology, 64(2), 141-154. doi: 10.1037/cou0000198

Constantine, M. G., Hage, S. M., Kindaichi, M. M., \& Bryant, R. M. (2007). Social justice and multicultural issues: Implications for the practice and training of counselors and counseling psychologists. Journal of Counseling \& Development, 85(1), 24-29. 
doi: 10.1002/j.1556-6678.2007.tb00440.x

Garriott, P. O., Raque-Bogdan, T. L., Yalango, K., Schaefer Ziemer, K., \& Utley, J. (2014). Intentions to seek counseling in first-generation and continuing-generation college students. Journal of Counseling Psychology, 64, 432-442. doi: 10.1037/cou0000210

Goodman, L. A., Liang, B., Helms, J. E., Latta, R. E., Sparks, E., \& Weintraub, S. R. (2004). Training counseling psychologists as social justice agents: Feminist and multicultural principles in action. The Counseling Psychologist, 32(6), 793-836. doi:

\section{$\underline{10.1177 / 0011000004268802}$}

Hatcher, R. L., Wise, E. H., \& Grus, C. L. (2015). Preparation for practicum in professional psychology: A survey of training directors. Training and Education in Professional Psychology, 9(1), 5-12. doi: 10.1037/tep0000060

Hayes, J. A., Youn, S. J, Castonguay, L. G., Locke, D. B., McAleavey, A. A., Nordber, S. (2011). Rates and predictors of counseling center use among college students of color. Journal of College Counseling, 14, 105-116. doi: 10.1002/j.2161-1882.2011.tb00266.x

Hernandez, P., \& McDowell, T. (2010). Intersectionality, power, and relational safety in context: Key concepts in clinical supervision. Training and Education in Professional Psychology,4(1), 29-35. http://doi.org/10.1037/a0017064

Kennan-Miller, D. (2019). Association of Psychology Training Clinics Director's Survey. Retrieved from https://aptc.org/?module=Home

Levy, J. J., Thompson-Leornadelli, K., Smith, K., Grant, N., \& Coleman, M. N. (2005). Attrition after intake at a university counseling center: relationship among client problem type, and time on waiting list. Journal of College Counseling, 8(2), 107-117. doi: 10.1002/j.2161-1882.2005.tb00077.x

Locke, L. A., \& Trolian T. L. (2018). Microaggressions and social class identity in higher 
education and student affairs. New Directions for Student Services, 162, 63-74. doi: $10.1002 /$ ss.20262

National Alliance on Mental Illness. (2012). College students speak: A survey report on mental health. Retrieved from https://www.nami.org/About-NAMI/Publications-Reports/Survey Reports/College-Students-Speak_A-Survey-Report-on-Mental-H.pdf

Orchowski, L.M., Castelino, P., Ng, H.M., Cosio, D., \& Heaton, J.A. (2011). The design and implementation of a counselor-in-residence program. Journal of College Student Psychotherapy, 25(3), 241-258. doi: 10.1080/87568225.2011.556968

Pieterse, A. L., Carter, R. T., Evans, S. A., Walter, R. A. (2010). An exploratory examination of the associations among racial and ethnic discrimination, racial climate, and trauma-related symptoms in a college student population. Journal of Counseling Psychology, 57(3), 255-263. doi: 10.1037/a0020040

Scheel, M. J., Stabb, S. D., Cohn, T. J., Duan, C., \& Sauer, E. M. (2018). Counseling psychology model training program. The Counseling Psychologist, 46(1), 6-49. doi: $10.1177 / 0011000018755512$

Shafranske, E. P., \& Falender, C. A. (2008). Supervision addressing personal factors and countertransference. In C. A. Falender \& E. P. Shafranske (Eds.), Casebook for clinical supervision: A competency-based approach (pp. 97-120). Washington, DC: American Psychological Association.

Smith, W. A., Allen, W., \& Danley, L. L. (2007). "Assume the position...you fit the description" Psychosocial experiences and racial battle fatigue among African-American male college students. American Behavioral Scientist, 51(4), 551-578. 
doi: $10.1177 / 0002764207307742$

U.S. Department of Education, Office of Planning, Evaluation and Policy Development and Office of the Under Secretary. (2016). Advancing Diversity and Inclusion in Higher Education. Retrieved from http://www2.ed.gov/rschstat/research/pubs/advancing-diversity-inclusion.pdf.

U.S. Department of Education, Office of Postsecondary Education (2008). A Profile of the Federal TRIO Programs and Child Care Access Means Parents in School Program. Retrieved from https://www2.ed.gov/about/offices/list/ope/trio/trioprofile2008.pdf

Vera, E. M., \& Speight, S. L. (2003). Multicultural competence, social justice, and counseling psychology: Expanding our roles. The Counseling Psychologist, 31(3), 253-272. doi: $10.1177 / 0011000003031003001$

Xiao, H., Carney, D. M., Youn, S. J., Janis, R. A., Castonguay, L. G., Hayes, J. A., Locke, B. D. (2017). Are we in crisis? National mental health and treatment trends in college counseling centers. Psychological Services, 14, 407-415. doi: 10.1037/ser0000130

Xiao, H., Castonguay, L. G., Janis, R. A., Youn, S. J., Hayes, J. A., Locke, B. D. (2017). Therapist effects on dropout from a college counseling center practice research network. Journal of Counseling Psychology, 64(4), 424-431. doi: 10.1037/cou0000208

Zivin, K., Eisenberg, D., Gollust, S. E., \& Golberstein, E. (2009). Persistence of mental health problems and needs in a college student population. Journal of Affective Disorders, 117, 180-185. doi:10.1016/j.jad .2009.01.001 